\title{
CONSIDERAÇÕES SOBRE EDUCAÇÃO PERMANENTE EM SAÚDE: REVISÃO BIBLIOGRÁFICA
}

\section{CONSIDERATIONS ON CONTINUING EDUCATION IN HEALTH:}

\author{
BIBLIOGRAPHIC REVIEW
}

Beatriz Ravazine ${ }^{1}$

Sandra Fogaça Rosa Ribeiro²

\section{Resumo}

Este estudo identificou publicações de 2008 a 2014 da área de Educação Permanente em Saúde com o objetivo de analisar produções científicas sobre Educação Permanente em Saúde no contexto de gestão do Sistema Único de Saúde. O referencial teórico utilizado foi proveniente das Ciências Sociais e Saúde Coletiva. A metodologia foi de natureza qualitativa, se constituiu de pesquisa bibliográfica em artigos científicos de base de dados LILACS que foram analisados com base nos pressupostos da Educação Permanente em Saúde, procurando responder à pergunta de pesquisa: De que forma os pilares da Educação Permanente em Saúde - controle social, gestão, ensino, atenção aparecem em artigos sobre Educação Permanente em Saúde? Os resultados e discussões possibilitaram perceber a importância dos pilares da Educação Permanente em Saúde no processo de construção da saúde pública no Brasil. As conclusões mostraram a pertinência de investimentos em planos de divulgação da Educação Permanente em Saúde, de forma a reafirmar sua importância para toda comunidade e fortalecer os pilares, possibilitando difundir os espaços potenciais da educação através da troca de conhecimentos na comunidade acadêmica, profissional e social.

Palavras-chave: Educação. Políticas Públicas em Saúde. Pessoal de saúde. Trabalho.

\footnotetext{
${ }^{1}$ Universidade Federal da Grande Dourados. E-mail: bia_rava@hotmail.com

${ }^{2}$ Doutora em Educação pela Faculdade de Educação da UNICAMP (2011). Atualmente é professora adjunta da Universidade Federal da Grande Dourados (UFGD). E-mail: sandrafogaca@ufgd.edu.br
} 


\section{Abstract}

This study identified publications from 2008 to 2014 in the area of Permanent Education in Health with the objective of analyzing scientific productions on Permanent Health Education within a context of management of the Unified Health System. The theoretical reference used came from the Social Sciences and Collective Health. The methodology for the qualitative evaluation is constituted by bibliographical research in the scientific bases of data LILACS. How the pillars of Permanent Education in Health - social control, management, teaching, attention - appear in articles about Permanent Education in Health? The results and discussions made it possible to understand the importance of the pillars of Permanent Education in Health in the process of building public health in Brazil. The conclusions show a pertinence of investments in plans of dissemination of Permanent Education in Health, in order to reaffirm its importance for the whole community and strengthen the pillars, allowing to spread the potential spaces of education through the exchange of knowledge in the academic, professional and social community.

Key-words: Education. Public Policies in Health. Health Personnel. Work.

\section{INTRODUÇÃO}

É oportuno contextualizar esta revisão bibliográfica na política de Educação Permanente em Saúde (EPS), que é de responsabilidade da Secretaria de Gestão do Trabalho e da Educação na Saúde, vinculada ao Ministério da Saúde, desde setembro de 2003. O Departamento de Gestão da Educação na Saúde (DEGES) assumiu o principal papel na organização de ações junto aos diversos órgãos envolvidos no processo, desde o próprio Ministério da Saúde até as Secretarias de Saúde dos municípios, articulando parcerias com diversas entidades como o Ministério da Educação, entidades de profissionais de ensino das profissões de saúde e outros (BRASIL, 2004). A forma como a EPS se compõe na rede de atenção em saúde do Sistema Único de Saúde (SUS) é bem diversificada, conforme a realidade vivenciada nas 
distintas regiões do Brasil. Entretanto, o que a torna semelhante, frente a essa heterogeneidade, é que pressupõe o processo de trabalho, enquanto espaço de formação, na tentativa de tornar-se mais participativa, oferecendo mais protagonismo aos atores envolvidos, a despeito de muitas dificuldades e embates inerentes aos processos coletivos. (HELOANI; RIBEIRO, 2011).

A EPS se organiza em locorregiões, antes divididas em polos, instâncias interinstitucionais que compreendem diversos atores. Dentre eles, as instituições formadoras, os gestores e os próprios trabalhadores, que devem compor as rodas para o caminhar do processo (BRASIL, 2004). Segundo Ceccim (2005), até julho de 2005 foram organizados em todo o país 105 Polos. A expectativa do autor é que isso possibilitasse a transformação do Sistema Único de Saúde numa rede-escola, tendo a formação um lugar central nas políticas de saúde. Conforme previsto no Pacto pela Saúde (BRASIL, 2009) e, recentemente, no Contrato Organizativo de Ação Pública - COAP (BRASIL, 2014), ainda há a necessidade de esforços e avanços para o funcionamento efetivo da Educação Permanente em Saúde, fundamental para subsidiar tal transformação. Atualmente a EPS é articulada por meio de Núcleos de Educação Permanente em Saúde (NEPS), os quais debatem as demandas numa microrregião, com representantes de diversos segmentos - instituições acadêmicas, gestores estaduais e municipais de educação, trabalhadores do SUS, Instituições de Ensino com cursos na área da saúde, movimentos sociais de saúde e do controle social no SUS. Esses representantes, num nível macrorregional, compõem Comissões de Integração Ensino-Serviço (CIES) que caminham para formar trabalhadores que integrem representativamente e democraticamente a questão da formação no SUS, fazendo uma troca de 
saberes numa perspectiva ampla do conhecimento (BRASIL, 2007). A troca de saberes deve acontecer no cotidiano de saúde, a fim de possibilitar a construção de conhecimentos em espaços diferenciados daqueles nos quais ocorrem cursos e capacitações, num formato de educação continuada. A EPS deve trazer atualizações constantes que são geradas nas reflexões dos próprios participantes. Esses espaços devem se desenvolver dentro de um enfoque transformador, numa concepção na qual a educação não é algo estático, mas um processo construído a partir da relação homem-mundo (FREIRE, 1980). É a "realização do encontro entre o mundo de formação e o mundo de trabalho, onde o aprender e o ensinar se incorporam ao cotidiano das organizações e ao trabalho" (BRASIL, 2004). Luckesi (1999) corrobora com essas ideias, afirmando que formação se faz no dia-a-dia, "atuando no e com o mundo e meditando sobre essa prática", desenvolvendo atitudes críticas sobre a realidade.

São dessas concepções de formação que derivam as confluências da Educação Permanente em Saúde com o mundo do trabalho, pois é exatamente no processo dinâmico do trabalho que a troca de experiência ocorre. Dessa forma, as contribuições das Ciências Sociais e da Saúde Coletiva convergem para o entendimento do assunto tratado neste artigo, por meio do referencial teórico exposto a seguir.

Justamente porque a EPS é o encontro do trabalho com o mundo da formação, é preciso entender o conceito de trabalho, desenvolvido a seguir. Para tanto, se apresentará o mundo do trabalho e que influências históricas ele traz, inserido no contexto trabalhista neoliberal. Primeiro, é necessário esclarecer que dentre as possiblidades de conceituação do termo, as autoras 
definem trabalho como a transformação da natureza para benefício do homem (MARX, 1975). É preciso levar em consideração que o trabalho constitui o homem, por ser uma categoria central de humanização, diferenciando o ser humano dos animais. Entretanto este universo é perpassado por influências políticas, econômicas e sociais que modificaram e acarretaram repercussões nefastas nesse benefício que o trabalho poderia conceder ao sujeito. Tais repercussões podem ser encontradas nas práticas do cotidiano do trabalho, nas relações sociais, na relação com a saúde e com a vida. (HELOANI; RIBEIRO, 2011).

Todas as formas de trabalho estão num contexto mais amplo - o mundo do trabalho - influenciadas pelo capitalismo, consolidado no final do século XVIII, que propunha liberdade para venda e compra de bens e mão de obra, o que é uma falácia, pois embora a industrialização tenha trazido mudanças e crescimento, a desigualdade e a pobreza cresceram com seu advento, logo após a Segunda Guerra Mundial (ANTUNES, 2015). Se antes o trabalho era uma atividade para fazer o homem feliz, com o avanço do capitalismo, o processo de alienação subordinou o trabalho ao capital, desfavorecendo a vida laboral. Nesse sentido Antunes (2009, p. 132) conceitua alienação como “a luta do capital para subordinar o trabalho, é a luta incessante do capital pelo poder [...] o processo de alienação é vivenciado cotidianamente pelo trabalho". Por outro lado, a desalienação é fundamental, pois "é parte imprescindível desse processo, é a incessante rebelião da atividade contra a passividade do ser". (ANTUNES, 2009, p. 132).

É nesse universo laboral contraditório que a EPS está inserida, com repercussões em seu processo. A prática de estudar, se capacitar formalmente 
e iniciar um trabalho no Sistema Único de Saúde, pode, de maneira equivocada, parecer simples e vir a se tornar algo mecânico e desconectado da realidade na qual esse profissional está inserido. O período acadêmico, os cursos de capacitação e os vários programas criados para melhorar a formação dos trabalhadores da saúde, trazem muitos benefícios à atuação deles, mas por muitas vezes são descontextualizados da realidade territorial, o que gera dificuldades na atuação desses profissionais. Estar inserido nesse sistema, o qual carrega consigo uma história de conquistas, trouxe um novo debate e uma nova maneira de se pensar essa educação e a atuação desses atores. $\mathrm{O}$ SUS necessita de profissionais que deem continuidade às inúmeras transformações pelas quais o país passou e as que ainda precisam acontecer. Atores, que durante a sua formação, tenham conhecimento do funcionamento integral da realidade e que depois continuem a se desenvolver de maneira permanente, compartilhando entre si situações de conforto ou desconforto, ideias de soluções, tudo para contribuir no trabalho. Com essa demanda, surge a política de Educação Permanente em Saúde. (BRASIL, 2005).

Campos, Cunha e Figueiredo corroboram com essas ideias, apresentando a perspectiva teórica Paideia, a qual explica a organização dos Sistemas Sociais de Saúde. As três dinâmicas por eles apresentadas trazem o caráter ideológico cultural, os componentes estruturais e organizacionais concretos de uma estrutura social e os sujeitos da trama política que operam tal estrutura e as colocam em funcionamento. A prática Paideia, sob esses três aspectos, objetiva agir de forma democrática e busca promover a democracia entre os sujeitos, contribuindo na autonomia destes em sua dinâmica social. Autonomia, nesse contexto, vai além de uma definição casual, é tida como 
“[...] capacidade do sujeito de reconhecer e lidar com a rede de dependência na qual estamos todos inevitavelmente mergulhados". (CAMPOS; CUNHA; FIGUEIREDO, 2013, p. 32).

Ainda Campos, Cunha e Figueiredo (2013) revelam que a busca pela autonomia e intervenção dos sujeitos no contexto em que vivem se expressa por meio da prática reflexiva. Esta os revela como sujeitos participantes e atuantes na dinâmica em que antes estavam submetidos e os apresenta como cidadãos. Essa reorganização que os autores propõem, é simplificada em uma palavra que utilizam frequentemente: a cogestão. Os autores apresentam o materialismo histórico e a psicanálise como pensamentos dialéticos que remetem a temas intrínsecos à cogestão. O interesse da classe dominante é que a sociedade que sofre com a divisão de classes, não saiba e nem traga à consciência a posição à qual estão submetidos, pois tal situação a sustenta no poder.

Os autores trazem também um importante conceito que é a coprodução, que advém dessa relação mundo-homem. Reconhecem o ser humano como quem está em determinado estado, mas que é ao mesmo tempo uma construção contínua da relação mundo-homem. E dessa contradição apontam uma possível saída que se direciona na tentativa de "lidar com suas múltiplas determinações e procura não negar o conflito, mas colocá-lo em análise para a construção de pactos e contratos" (CAMPOS; CUNHA; FIGUEIREDO, 2013, p.20). Nessa tentativa de lidar com as múltiplas determinações, os sujeitos enfrentam as determinações próprias, mas também aquelas que são externas ao seu contexto, limitando sua liberdade, incluindo as contradições antes apontadas pela divisão de classes. 
Campos, Cunha e Figueiredo (2013) destacam as dificuldades para encontrar atores que colocassem em prática essas propostas apresentadas acima, as quais assumiriam tais embates na busca por mudanças. Os próprios autores respondem a essa questão, apresentando critérios que perpassam um reconhecimento do bem-estar e da justiça social, por meio da política, trabalho e gestão; os mesmos deveriam, segundo eles, ser encarados como a possibilidade de proporcionar autonomia e liberdade para as pessoas e instituições; e por fim, assegurar a resolução de conflitos e a elaboração de contratos com o menor uso de violência possível. Essas concepções e práticas promovem igualdade e participação dos sujeitos em seu desenvolvimento no contexto que o cerca, possibilitando um compartilhamento de concepções, que auxilia na definição de sua atuação, descrevendo-a e exemplificando-a. Assim, busca um compromisso social e democrático, contando com uma democracia institucional, um olhar crítico à herança taylorista no momento atual e com a coprodução do sujeito, promovendo assim a equidade e o combate à injustiça.

Ceccim e Feuerweker (2004) convergem com essas ideias, preocupandose com a distância da realidade da gestão na formação dos profissionais da saúde, o que a torna impermeável ao controle social. Recorrem aos princípios organizativos e doutrinários do SUS, de construção descentralizada do sistema, universalidade, integralidade e participação popular para orientarem a construção dos quatro pilares da Educação Permanente em Saúde: gestão, atenção, controle social e ensino da EPS. Logo a seguir, esses pilares serão expostos de forma conceitual.

A construção descentralizada do sistema - a gestão, primeiro pilar - se compõe pelas três esferas do governo: municipal, estadual e federal- 
responsáveis por contribuir nas atividades da Educação Permanente em Saúde. Ao se preocupar com a integralidade, a EPS se fortalece por meio do segundo pilar - o trabalho de atenção à saúde - exercida pela equipe multiprofissional, intersetorial, focando a realidade na qual os usuários vivem. Conjuntamente surge o controle social que é o terceiro pilar da EPS. Os usuários podem problematizar, reorganizar e transformar o setor junto com os profissionais e estudantes através da participação popular. O quarto e último pilar é o do ensino, que procura diluir a distância da formação dos profissionais de saúde das práticas de saúde pública, busca aproximar esses saberes das demandas e dificuldades que o SUS enfrenta.

O ensino, enquanto último pilar é fundamental para esta pesquisa, representado por vários segmentos - o conhecimento popular em saúde da comunidade, o saber acadêmico e outros - podendo transformar o trabalho em formação e educação em serviço (CECCIM; FEUERWEKER, 2004). A ênfase do ensino deve ser a prática, em detrimento de teorizações e sistematizações distantes do dia-a-dia. Esse direcionamento fica claro no seguinte trecho de um documento sobre a EPS:

os diversos atores deverão desenvolver novas propostas pedagógicas, que sejam capazes de mediar a construção do conhecimento e dos perfis subjetivos nesta perspectiva. Para que os serviços possam, efetivamente, tornar-se espaços de aprendizagem serão necessários novos mecanismos de planejamento e de gestão. (BRASIL, 2004, p. 16).

Ainda no mesmo documento, ressalta-se a importância das metodologias ativas no processo de ensino dentro do contexto da EPS, numa articulação entre o sistema de saúde e as instituições formadoras, propondo a "adoção de metodologias ativas de ensino e aprendizagem e a formação geral, 
crítica e humanística, sob a perspectiva da multiprofissionalidade e transdiciplinaridade". (BRASIL, 2004, p. 24).

Esta revisão bibliográfica teve como objetivo analisar produções científicas sobre Educação Permanente em Saúde no contexto de gestão do SUS. Ressalta-se que esta revisão colaborou em vários projetos vinculados ao Grupo de Pesquisa "Saúde Mental, Trabalho e Gestão", sendo um deles financiado pela FUNDECT/Edital 04/2013 - PPSUS/MS, denominado “Educação Permanente em Saúde: processo de gestão e formação num núcleo regional de saúde do Mato Grosso do Sul".

\section{MÉTODO}

A pesquisa foi de revisão bibliográfica, seguiu uma abordagem qualitativa, apropriada para este estudo por possibilitar compreender o sentido apresentado nas publicações por meio de um processo narrativo e compreensivo, com base nos pressupostos conceituais da Educação Permanente em Saúde. Segundo Minayo (2010) o verbo compreender, muito utilizado na abordagem qualitativa, é um exercício crítico, destacando e analisando os conceitos e posicionamentos utilizados pelos diferentes autores.

A seleção dessas publicações baseou-se numa busca na base de dados LILACS, seguindo os descritores: Educação, Políticas Públicas em Saúde, Pessoal de Saúde, Trabalho. Os descritores foram retirados do vocabulário sistematizado e trilíngue dos Descritores em Ciências da Saúde (DeCS) para a busca eletrônica, respeitando os conceitos principais da pesquisa, bem como os objetivos. Ressalta-se que foi feito o cruzamento dos descritores, empregando o operador lógico AND. A busca foi realizada durante os meses de fevereiro e 
março de 2016. A pergunta de pesquisa que orientou essa busca foi: De que forma os pilares da EPS - controle social, gestão, ensino, atenção - aparecem em artigos sobre EPS?

Inicialmente foram encontradas 42 publicações, que foram submetidas aos seguintes critérios de inclusão: Publicações entre os anos de 2008 a 2014; publicações que relatem pesquisas empíricas; Publicações com resumos nas quais haja o relato explícito sobre Educação Permanente em Saúde ou Educação em Saúde. Em seguida, também foram submetidas aos critérios de exclusão, os quais foram: Teses, Monografias; publicações em outras línguas. Por meio desses recortes, obteve-se o um total de cinco publicações, as quais compuseram o corpus desta pesquisa.

Duas pessoas fizeram a busca, a orientadora da pesquisa e a própria pesquisadora, desempenhando a função de juízas, as quais discutiram e esclareceram dúvidas no processo, com base na pergunta de pesquisa e nos critérios de inclusão e exclusão preservando a fidedignidade na coleta dos artigos.

A análise seguiu as etapas propostas por Minayo (2010), incluindo: 1) Pré-análise, por meio de uma leitura caracterizada por uma atenção flutuante. Assim, a subjetividade do pesquisador e a do pesquisado se integraram numa unidade contextual; 2) Exploração do material, através de várias leituras, descobrindo orientações para a análise propriamente dita; 3) Tratamento dos resultados obtidos e interpretação, realizados através da busca do sentido latente ou subjacente e correlação com os conceitos sobre a temática.

\section{RESULTADOS}


O artigo “Formulação da política de Gestão do Trabalho e Educação na Saúde: o caso da Secretaria Estadual de saúde da Bahia, Brasil, 2007 - 2008" (PINTO; TEIXEIRA, 2011) analisou o processo de formulação da Política de Gestão do Trabalho e Educação na Saúde (PGETES), desenvolvido pela Secretaria Estadual de Saúde da Bahia (SESAB). O processo contou com a participação de usuários e trabalhadores e com a contribuição da Superintendência de Recursos Humanos priorizando essa área por ser uma das questões que requisitava mais atenção. Considerando os avanços e dificuldades em sua secretaria, decidiu tomar essas experiências como ponto de partida para a criação da política.

O artigo "Qualificação de Agentes Comunitários de Saúde: instrumento de inclusão social" (MELO et al., 2009) investigou as contribuições dos Agentes Comunitários de Saúde (ACS) ao participarem do Programa de Qualificação e Desenvolvimento Profissional. Analisa o processo de Educação Permanente em Saúde que ocorre com esses profissionais, seguido de melhora na autonomia e atuação saudável por parte deles.

O artigo "Considerações Sobre o Mestrado Profissional em Gestão do Trabalho e da Educação na Saúde" (AMÂNCIO FILHO; OLIVEIRA; VIEIRA, 2012) analisou as contribuições do Mestrado em Gestão do Trabalho e da Educação em Saúde da Escola Nacional de Saúde Pública Sergio Arouca compreendendo-o como um instrumento de enfrentamento das dificuldades e desafios na formação de recursos humanos para a saúde.

O artigo "Educação Democrática e sua aplicação ao campo da saúde" (LEFEVRE; LEFEVRE; CAVALCANTI, 2015) trata do tema educação democrática de forma a conceituá-la tanto por parte dos profissionais quanto 
dos usuários. Coloca a educação como processo autônomo de tomada de decisões que podem ser facilitadas por um educador. Traz também as dificuldades de aplicação dessa educação democrática.

O artigo "Educação popular, ações em saúde, demandas e intervenções sociais: o papel dos Agentes Comunitários de Saúde" (MALFITANO; LOPES, 2009) analisou a intervenção de ACS considerando a relação entre a militância em movimentos sociais e a atuação na região do centro expandido da cidade de São Paulo (SP) - região do Brás e do Belém, onde se localizam cortiços e movimentos de luta popular por moradia. Concluem que os ACS são lideranças dessa região e atuam como elo entre o serviço e a comunidade sendo também personalidades importantes na educação popular.

\section{DISCUSSÃO}

A apresentação e análise dos resultados foram realizadas por meio de uma reflexão crítica a respeito das publicações, tomando como referencial os pressupostos e definições de Educação Permanente em Saúde e do mundo do trabalho, apresentados na perspectiva da Saúde Coletiva e das Ciências Sociais.

Alguns aspectos conceituais sobre o termo - Recursos Humanos utilizados por vários autores dos artigos selecionados, merecem alguns apontamentos. Cabe uma consideração sobre tal uso, pois é uma nomenclatura ideológica, empregada por áreas do conhecimento como a Psicologia Organizacional, que tiveram por muito tempo o foco numa prática excludente, a partir de um processo de recrutamento e seleção, seguido de ações denominadas treinamento que priorizavam o aumento desenfreado da 
produção em detrimento do bem-estar do trabalhador (SAMPAIO, 2009). Em geral, as publicações, apesar de usarem esse termo, ideologicamente comprometido, apresentam a questão como um "nó crítico", ampliando a compreensão do problema para além do aumento da produtividade, propondo a relação do problema outras questões como gestão e processo de trabalho. Pinto e Teixeira (2011) sugerem a troca e mudança de gestão como principais responsáveis pela resolução desse problema. Filho, Oliveira e Vieira (2012) apontam um caminho mais focado na formação formal. Sugerem que uma das soluções para as questões difíceis relacionadas a recursos humanos deveriam ser resolvidas por meio da criação do mestrado em Gestão do Trabalho e da Educação na Saúde. Trazem o conceito de formação em recursos humanos como demanda política e compromisso social, em que saúde e educação necessitam formar parcerias para que tratem os recursos humanos de maneira conjunta, visando sanar as questões específicas encontradas:

A complexidade da aprendizagem vem permitindo identificar desafios específicos, dentre eles: a) formar profissionais com foco no conceito ampliado de saúde; b) realizar cursos por estado ou região; c) articular parcerias com outras instituições de ensino superior; d) aproximar os estudos conduzidos pela academia e as demandas existentes no mundo do trabalho. (AMÂNCIO FILHO; OLIVEIRA, VIEIRA, 2012 p. 111).

Nesse sentido, os autores relatam que foi necessário repensar uma gestão do trabalho e da educação na saúde que se preocupasse com o processo de educação na formação de gestores e trabalhadores do SUS, que fortalecesse as diretrizes e princípios do SUS. Entre as medidas - num enfoque na formação de gestores para o SUS e trabalhadores do SUS - surge o Mestrado Profissional em Gestão do Trabalho e da Educação em Saúde, como estratégia para atender 
as necessidades enunciadas acima, integrando teoria e prática por meio de aulas, seminários, encontros e fóruns.

A Política de Educação Permanente em Saúde surgiu seguindo questões compatíveis às preocupações citadas no artigo de Filho, Oliveira e Vieira (2012). Buscou auxiliar no processo de formação permanente dos atores, para que tivessem conhecimento do funcionamento de forma integrada a sua realidade. Há que se refletir que embora um mestrado possa ser útil, se caracteriza mais como uma educação continuada do que como uma educação permanente, com possibilidades tímidas para gerar mudanças extensas, mas apenas pontuais. É importante repensar como a Educação Permanente pode ser referenciada nessa publicação. De modo que não se permita a perpetuação de concepções equivocadas ao que se considera EPS e do que se pode declarar Educação Continuada. O recurso de inserção do Mestrado Profissional em Gestão do Trabalho e da Educação em Saúde é favorável à formação de profissionais preocupados com atuação e formação no SUS, entretanto as preocupações relacionadas à formação profissional não devem limitar-se apenas ao período de graduação ou pós-graduação. Para que a EPS aconteça ela deve estar articulada com o dia a dia desses profissionais de modo que a formação aconteça e cresça no aproveitamento das aprendizagens geradas durante a atuação.

Percebe-se por meio de algumas publicações abordadas neste estudo, o envolvimento da gestão, um dos pilares da EPS, nas esferas dos governos municipal, estadual e federal. Especialmente a estadual, é apresentada com um papel principal na contribuição das atividades da Educação Permanente em Saúde. A atuação da gestão descrita por Pinto e Teixeira (2011) possibilitou 
perceber que um estreitamento das relações, envolvendo os colegas de trabalho e a secretaria de saúde nas decisões tomadas, por meio da promoção de diálogo e da valorização de opiniões divergentes. Ainda os mesmos autores discutem sobre os espaços de escuta das questões dos profissionais da área da saúde, que resultaram na valorização dos saberes. A utilização de oficinas, um dos exemplos das produções de momentos em que a EPS concretiza-se, foi então instrumento de compartilhamento, possibilitando a identificação de problemas na manifestação de propostas dos dirigentes. É nessa perspectiva que Campos, Cunha e Figueiredo (2013) apresentam a cogestão vinculada a uma prática de co-produção. Indo ao encontro com a prática reflexiva, os autores colocam a racionalidade dialética como outro constituinte da cogestão. Esta coloca a sociedade com um constante afetar-se pelo outro e pelo todo que o cerca, trazendo o sujeito e a sua permanente construção. Indivíduo e coletivo se completam. Este contexto coincide com a educação permanente por trazer a formação dos trabalhadores como uma troca contínua que acontece na relação homem-trabalho.

Foi possível visualizar nas publicações de Pinto e Teixeira (2011) os resultados gerados pelos momentos de EPS. As oficinas, assim como tantos outros momentos do cotidiano do trabalho, são possíveis espaços de Educação Permanente, que mesmo não recebendo essa nomenclatura nas produções, promovem educação no momento em que os participantes podem alimentarse das dúvidas, dilemas e sugestões dos outros, sendo essas questões fundamentais para promoção da formação permanente dos trabalhadores envolvidos. (RIBEIRO; MARTINS; CAMPOS, 2015). 
Melo, Brant, Oliveira e Santos (2009) corroboram com esse entendimento quando citam programas de qualificação e desenvolvimento profissional dos ACS por meio de cursos em escolas profissionalizantes do SUS. Embora estejam focando o desenvolvimento como algo institucional, os autores mostram que mesmo nesses espaços de produção de saber formal, é possível acontecer EPS. É que acontece nesses espaços a valorização do saber empírico dos profissionais, e em seguida ganho de autonomia para eles. O programa de qualificação possibilitou valorização do saber do ACS, permitindo que ele fosse reconhecido pela comunidade em que vive.

Apesar das produções de Pinto e Teixeira (2011), e Melo, Brant, Oliveira e Santos (2009) defenderem avanços na formação, por meio de ações que denominam de Educação Permanente em Saúde, parece que aquilo que tratam nos artigos se aproxima mais de um processo de Educação Continuada, talvez insuficientes para gerar mudanças extensas de educação em saúde. É importante nesse momento, diante de uma revisão bibliográfica em Educação Permanente em Saúde, que se pontue as concepções equivocadas, como as que declarem EPS sinônimo de Educação Continuada. A segunda se refere a cursos e capacitações para o trabalhador num modelo acadêmico, diferentemente da EPS que tem a proposta de uma formação não verticalizada, um repensar do processo de trabalho no dia-a-dia. (BRASIL, 2005; MERHY, 2005).

Reforçando as limitações dos cursos de capacitações, característicos da educação continuada, cabe mencionar que são previamente definidos, em geral mecanizados, enquadrados em técnicas verticalizadas e descontextualizados da prática profissional. Por realizar-se de forma 
verticalizada, um profissional transmitindo conhecimentos aos outros, na educação continuada não ocorre como uma troca de saberes entre os atores. Fragmenta-se mais o trabalho, por meio da aquisição de técnicas individualizantes (CAMPOS; CUNHA; FIGUEIREDO, 2013). As capacitações acontecem com data marcada, seguindo uma programação rigidamente planejada, através de um pedido da gestão. $O$ profissional destinado a comandar o encontro, grande parte das vezes, não atua no mesmo local que esses trabalhadores, o que dificulta o entendimento dos casos que aqueles profissionais enfrentam no cotidiano, particular de cada região. (BRASIL, 2007).

Neste momento, cabe uma reflexão mais detalhada acerca da rigidez do planejamento exposto acima. Se a Educação Continuada, limitada pelo excesso de formalização e planejamento prévio, não é algo que promova as transformações do SUS, é pertinente ponderar se a Educação Permanente em Saúde conseguirá se efetivar, sem nenhuma forma de planejamento. Merhy (2015), destaca que não há necessidade de intencionalidade para que a Educação Permanente aconteça, sendo ela um afetar-se informal do saber e práticas do outro, que vai de encontro com a produção de saberes. Em contrapartida, Heloani e Ribeiro (2011) destacam que o sofrimento psíquico que os trabalhadores vivenciam acarretam mecanismos de defesa ou enfrentamentos que repercutem desfavoravelmente nas relações de trabalho, mesmo as espontâneas, em espaços informais como a cozinha ou corredores, dificultando que a EPS ocorra de forma espontânea. Assim, mostra-se necessária a criação de espaços coletivos que oportunizem as trocas de experiências para que a Educação Permanente aconteça. Talvez seja necessário 
ter um planejamento específico também para que tais momentos ocorram, mesmo que de forma menos rígida e contextualizada ao lugar de tempo disponível de cada posto de trabalho.

Notou-se, durante a revisão, ausência de publicações que comentem sobre o controle social como um pilar que sustente o agir do usuário do SUS. São raras as produções que citam o usuário da saúde pública como participante ativo desse sistema. É lamentável essa lacuna, pois a histórica de luta do povo brasileiro durante a Reforma Sanitária é que resultou na conquista de um Sistema Único de Saúde. Somente com o fortalecimento do controle social, com o protagonismo dos usuários, é possível dar continuidade nas inúmeras transformações que esse sistema necessita. Rolim, Cruz e Sampaio (2013) expõem essa dificuldade da população em exercer o controle social, por meio da participação popular nos espaços diversos como reuniões nas unidades de saúde, Conselhos, Conferências e das audiências públicas, apontando a falta de interesse de alguns na divulgação dos direitos que as classes sociais possuem.

As produções de Malfitano e Lopes (2009) tratam da participação da comunidade, ao discutirem o papel do ACS, que adquire característica social militante nas comunidades, no momento em que buscam com a equipe soluções aos problemas que a comunidade lhes apresentou, em situações de visitas domiciliares ou ao serem abordados na rua. O problema é que essa participação da comunidade, viabilizada pelo ACS, parece ser a única via de participação da população na promoção da saúde (MALFITANO; LOPES, 2009). É fato que o trabalho do ACS inclui buscar opções de melhora da saúde na comunidade, entretanto, não deveria ser motivado pela dificuldade dessa 
comunidade encontrar parceria na equipe de saúde para resolver os problemas. O ACS toma para si atribuições que não seriam dele, mas da comunidade, exercendo, muitas vezes, ele mesmo o controle social, o que deveria ser feito pelos usuários. Ao invés disso, a militância social desses agentes é confundida com desvios de funções, que os colocam em situações de "tapa-buracos", permitindo que a comunidade os requisite em horários fora do trabalho, invadindo sua vida pessoal. O agravante é que os demais membros da equipe de saúde não se envolvem da mesma forma com os usuários, tornando o ACS cada vez mais refém dessa relação distorcida. Dessa forma, o trabalho que deveria ser benéfico e constituinte de um processo de vida saudável, se transforma em algo nefasto, com repercussões prejudiciais ao processo de trabalho e a comunidade, que acaba perdendo a oportunidade de se protagonizar como co-participante de produção de saúde, transferindo para outrem essa atribuição. (ANTUNES, 2015).

A atenção à saúde, que teria como principal protagonista o trabalhador de saúde, mostra-se como um pilar pouco explicitado nas produções aqui revisitadas, não possibilitando ampliar o debate à como se dá a construção da relação dos trabalhos. Foi visto que a ausência da atenção por parte de determinados profissionais afeta na construção da subjetividade e alteridade de outros, no caso os ACS, que tomam parar si questões que não lhes competem. Este pilar fundamental da EPS deveria envolver as atividades dos profissionais de forma multiprofissional, visando uma melhor atuação e atendimento ao usuário, integrando os conhecimentos de diversos profissionais à realidade que o usuário vive. (RIBEIRO; MARTINS; CAMPOS, 2015). 
Lefevre, Lefevre e Cavalcanti (2015) trazem em suas publicações a educação democrática como assunto tanto da equipe, quanto dos usuários, onde educação é um processo autônomo, de tomada de decisões que podem ser facilitadas por um educador. Nesse momento o pilar da EPS, o ensino é contemplado por estes autores num movimento de construção de um processo educativo como ponto de partida para uma educação permanente. Os mesmos autores apresentam o sujeito como alguém que pode receber informação técnica e ser livre a escolher diante da promoção de diálogo, podendo assim através do controle social ser ativos na transformação do atendimento. As produções dos autores já citados anteriormente, Amâncio Filho, Oliveira, Vieira (2012), embora de forma mais próxima de uma educação continuada, fomentam o pilar do ensino ao criarem um Mestrado Profissional em Gestão do Trabalho e da Educação na Saúde, com o objetivo de durante o processo formativo dos profissionais, apostar em uma educação permanente durante a formação. (MALFITANO; LOPES, 2009).

\section{CONCLUSÕES}

Os resultados deste estudo envolveram publicações que trataram desde gestão no trabalho, gestão na educação, educação democrática aplicada ao campo da saúde, educação popular, até o papel do ACS. A análise procurou ressaltar a presença ou não dos pilares da EPS nas produções, ressaltando a importância de reforçar esses pilares, tanto na comunidade acadêmica, profissional e social. Esse fortalecimento dos pilares possibilitaria difundir os espaços potenciais da educação através da troca de conhecimentos entre estes.

Cabe aqui enfatizar que a EPS não tem hora nem lugar prédeterminados para acontecer. Ela pode ser realizada em reuniões formais de 
processo de reformulação de planos, como também nos momentos informais que vão desde as conversas de corredor, até as reuniões deliberativas que os espaços promovem. A educação continuada poderia ser um passo para promover Educação Permanente, se possibilitasse momentos em que essa produção de saber formal abrisse espaço para questionamentos e deliberações.

Este estudo possibilitou identificar que a relação entre trabalho e EPS não tem sido muito desenvolvida nas publicações, sugerindo que essa dimensão não tem sido uma temática predominante nas pesquisas sobre EPS. Entretanto, tal questão causa um estranhamento, pois na perspectiva dos pilares da EPS o processo de trabalho é um contexto privilegiado de implementação da EPS.

Dentre as produções analisadas, não foram encontradas citações às locorregiões ou aos Núcleos de Educação Permanente em Saúde (NEPS), previstos a partir de 2007, bem como aos polos de Educação Permanente, modelo anterior de organização da EPS.

Reconhece-se que seria favorável ampliar o escopo de análise para outras bases de dados, além da utilizada nesta pesquisa, a fim de aprofundar os achados deste estudo. Entretanto, ficou perceptível que essa política avançou pouco desde sua criação e necessita de mais planos de divulgação, que desmistifiquem possíveis erros no entendimento da EPS para todos seus atores, incentivando diálogos sobre essa política, que ao trabalhar de forma horizontalizada promova a valorização dos conhecimentos cotidianos dos trabalhadores, gestores e usuários do SUS, permitindo desfazer equívocos relacionados à conceituação em momentos de trabalho no entendimento e na aplicação da EPS. 


\section{REFERÊNCIAS}

AMÂNCIO FILHO, A.; OLIVEIRA, S. P.; VIEIRA, A, L, S. Considerações sobre o mestrado profissional em Gestão do Trabalho e da Educação na Saúde. Saúde para Debate, n. 47, p. 111-116, maio, 2012.

ANTUNES, R. Os sentidos do trabalho: ensaio sobre a afirmação e a negação do trabalho. São Paulo, São Paulo, SP: Boitempo. 2009.

Adeus ao trabalho? Ensaios sobre as metamorfoses e a centralidade do mundo do trabalho. 16. ed. Campinas, SP: Cortez: 2015.

BRASIL. Ministério da Saúde. Secretaria de Gestão do Trabalho e da Educação na Saúde. Departamento de Gestão da Educação na Saúde. Política de educação e desenvolvimento para o SUS: caminhos para a Educação Permanente em Saúde: pólos de Educação Permanente em Saúde. Brasília, DF, 2004.

. Ministério da Saúde. A educação permanente entra na roda: polos de educação permanente em saúde, conceitos e caminhos a percorrer. Brasília, DF, 2005.

. Ministério da Saúde. Portaria GM/MS n. 1996 de 20 de agosto de 2007. Dispõe sobre as diretrizes de implementação da Política Nacional de Educação Permanente em Saúde e dá outras providências. Brasília, 2007.

. Ministério da Saúde. Política Nacional de Educação Permanente em Saúde. Brasília, DF, 2009.

BRASIL. Ministério da Saúde. Secretaria de Gestão Estratégica e Participativa. Departamento de Articulação Interfederativa. Guia para a elaboração do contrato organizativo da ação pública: construindo o COAP passo a passo. Brasília, 2014.

CAMPOS, G.W.S.; CUNHA, G. T.; FIGUEIREDO, M. D. Práxis e formação paideia: apoio e cogestão em saúde. São Paulo, SP: Hucitec, 2013. 
CECCIN, R. B.; FEUERWERKER, L. C. M. O Quadrilátero da Formação para a Área da Saúde: Ensino, Gestão, Atenção e Controle Social. Revista Saúde Coletiva, v.14, n.1, p. 41-65, jan./jun. 2004.

CECCIM, R.B. Educação permanente em saúde: descentralização e disseminação de capacidade pedagógica na saúde. Ciênc. Saúde Colet., v. 4, n. 10, p. 975-986, out/dez 2005.

FREIRE, P. Conscientização: teoria e prática da libertação, uma introdução ao pensamento de Paulo Freire. São Paulo, SP: Cortez \& Moraes, 1980.

HELOANI, J. R. M.; RIBEIRO, S. F. R. Sofrimento psíquico do agente comunitário de saúde: interfaces entre processo de trabalho, formação e gestão. Revista Rede de Estudo do Trabalho, v. 4, n. 1, p. 79-96, nov., 2011.

LEFEVRE, F.; LEFEVRE; A. M. C.; CAVALCANTI, C. C. T. J. Educação Democrática e sua aplicação ao campo da saúde. Sociedade Saúde, São Paulo, v. 24, p. 172-179, abr./jun. 2015.

LUCKESI, C. C. O papel da didática na formação do educador. In: CANDAU, V. M. (Org.). A didática em questão. Petrópolis, RJ: Vozes, 1999. p. 25-34.

MALFITANO, A. P. S.; LOPES, R. E. Educação Popular, ações em saúde, demandas e intervenções sociais: o papel dos agentes comunitários de saúde. Cad. CEDES, v. 29, n. 79, p. 361-372, set./dez. 2009.

MARX, K. O capital: crítica da economia política. Rio de Janeiro, RJ: Civilização Brasileira. 1975.

MELO, M. B.; BRANT, L. C.; OLIVEIRA, L. A.; SANTOS, A. P. S. Qualificação de Agentes Comunitários de Saúde: instrumento de inclusão social. Trab. educ. saúde, v. 7, n. 3, p. 463-477, nov., 2009.

MINAYO, M. C. S. O desafio do conhecimento: pesquisa qualitativa em saúde. 8ed. Rio de Janeiro, RJ: Hucitec, 2010. 
MERHY, E. E. O desafio que a Educação Permanente tem em si: a pedagogia da implicação. Interface: Comunic, Saúde, Educ, v. 9, n. 16, p.161-177, set. 2004/fev. 2005.

MERHY, E. E. Educação permanente em movimento: uma política de reconhecimento e cooperação, ativando os encontros do cotidiano no mundo do trabalho em saúde, questões para os gestores, trabalhadores e quem mais quiser se ver nisso. Revista Saúde em Redes, v.1, n.1, p. 7-14, jul. 2015.

PINTO, I. C. M.; TEIXEIRA, C. F. Formulação da Política de Gestão do Trabalho e Educação em Saúde. Cad Saúde Pública, v.27, n.9, p 1777- 1788, set. 2011.

RIBEIRO, S. F. R.; MARTINS, C. P.; CAMPOS, G. W. S. Cartilha Educação Permanente e redes de trabalho no SUS. Dourados, MS: UFGD, 2015.

ROLIM, L. B; CRUZ, R. S. B. L. C.; SAMPAIO, K. J. A. J. Participação popular e o controle social como diretriz do SUS: uma revisão narrativa. Saúde em Debate, v. 37, n. 96, p. 139-147, jan./mar. 2013.

SAMPAIO, J. R. A gestão das pessoas e a motivação: o Maslow desconhecido. Administração, v. 44, n. 1. jan./fev./mar. 2009.

Recebido: 29 de março de 2017

Aceito: 27 de abril de 2017

Publicado: 10 de maio de 2017 